\title{
Socio-Cultural Approaches in the Prevention of Drug Relapse: A Study in Rawalpindi, Pakistan
}

\author{
Asma Zafar \\ Sociology \& Anthropology Department, PMAS Arid Agriculture \\ University Rawalpindi, Pakistan
}

\author{
Aiaha Zafar \\ Department of Sociology, \\ G. C. University Faisalabad, Pakistan
}

Muhammad Asim

Department of Sociology,

G. C. University Faisalabad, Pakistan

Doi:10.5901/ajis.2013.v2n2p287

Correspondence Email: masim202@gmail.com

\begin{abstract}
Relapse is the restart the use of alcohol or other drugs after period of abstinence and is often accompanied by reinstatement of dependent symptoms. In Pakistan all the drug addiction control centre have a very high ratio relapse. The major causes of relapse are socio-economic, socio-cultural, family background, level of education, social environment and psychological condition. Relapse prevention is a set of therapeutic procedure employed cases of drug problems to help individual avoid or cope with lapses or relapses to un-controlled substance use. Majority of the respondents $82 \%$ become addict and relapse due to friends and bad company, $76 \%$ of the respondents were belonged from nuclear family system, Majority of $82 \%$ respondents become addict and relapse due to friends and bad company and $82 \%$ respondents were agreed that society play major role in spread of addiction and relapsing situation.
\end{abstract}

Keywords: Socio-cultural, Approaches, Prevention, Drug Relapse

\section{Introduction}

Drug abuse problems cause sustainable burden to almost all societies and it is vital to invest time and energy in responding to these problems. The community of drug abusers is a major problem through out the world and focus attention of all countries through the problem. The scope and speed of spread of drug addiction in the country is shocking the physical, psychological, mental and moral health of youth and even the future of large number of them. The social stability of society in the near future without discrimination of color and territory is one of the major existing problems at worldwide level today (Midgley, 1995). Along with these, the most important thing is to know about relapse, its prevention and control. In relapse prevention it is important to increase awareness for the potential of relapse. The main draw-back of sociological, socio-cultural and socio-psychological research for the reasons of drug addiction is not realizing the fact that reasons can be different at each stage of getting accustomed to drugs (Khalid et al., 2004). The predominant approach to understanding and preventing relapse is based on analyzing the situations in which relapse occurs. Some situations, such as negative mood states and the presence of drinking or smoking related cues, appear to be associated with a high risk of relapse. (Wanigaratne et al., 1990)

Relapse is symptoms of addiction, it is preventable. A key factor in preventing relapse is to improve social adjustment. The poor social adjustment by nominal offenders makes them especially from to relapse (Joe et al., 1985)

Drugs and alcohol addiction is a chronic and relapsing condition. Recovery requires changes in attitude, behavior and values. Because of these issues, recovery is not static condition it is ongoing process. Relapse occurs when attitude and behavior revert to ones similar to those exhibited when the person was actively using drugs and alcohol. Although 
relapse can occur at any time, it is more likely earlier in the recovery process. At this stage habit and attitude needed for continued sobriety, skill required to relapse substances use, and identity with positive peer are not firmly entrenched (Nowinski, 1990). Relapse prevention is based on communication and understanding between person experiencing mental illness their family and careers primary health care. The specialist mental health and community support services about access to support or treatment if there are early stages of relapse. Rehabilitation typically follows an initial phase of treatment in which detoxification and if required other medical and psychiatric treatment occurs. It compasses a variety of approaches including group therapy, specific behavior therapies to prevent relapse $(\mathrm{NMH}, 2002)$

The present study has focused on socio-cultural approaches in relapse prevention such as ethic background, gender, family, culture, occupation, law, media and religious affiliation. It has given us the ideas about different approaches through which we can decrease the relapse ratio. The main objectives of the study were:

- To find out the relationship between relapse and socio-cultural factors.

- To explain the effect of socio-cultural environment on drug misers in relapse.

- To explore the way through which we prevent drug misers from relapse.

\section{Materials and Methods}

The micro level study was based on primary data collected through field survey. The present was conducted in Rawalpindi city. The universe of the study consisted of "BANNI" area of Rawalpindi. By using purposive sampling technique, 100 respondents were selected from the area. To explore study objectives, a well-designed interviewing schedule was prepared to know the perception of drug miser about the relapse. Additionally, key informants, focus group discussions (FGD), and participant's observations were used to generate quantitative information for a better in depth knowledge of the issue. The data thus collected were analyzed by using appropriate statistical techniques. Descriptive statistics have been employed to draw the conclusion.

\section{Results and Discussion}

The research reveals that respondents had different literacy rates. Few complete schooling and reached college level. But the considerable point is that majority of the respondents did not go for further education after matriculation. Illiterate and less educated people had different concept about life and are not aware that what sort of cause could create problems for family and community. Other aspects that attract these people to drug use were easy availability of ordinary drugs which are used all over Pakistan. Better educated people are less prone to drug use because of awareness of its bad effects. During research it was found that drivers especially truck driver's use various type of drugs in the distribution of respondents regarding to their occupation. During the study it was found that in bachelor people, the socio-cultural, psychological and social causes of drug abuse were much higher as compared to married people abusing drugs with similar cases. Most of the drug abusers are from urban residential background $65 \%$. Because social life of urban areas is more stressful, sedentary lifestyle, congested cities, social problems weak social relation, unemployment and availability of drugs. All these factors constitute to frequency of drug abuse and relapse in urban area areas. $64 \%$ of the respondents were belonged to nuclear family system. $76 \%$ of the respondents had a normal family system which is usually typical and acceptable by all family members and they are not suffering from any mental tension due to this quality the people go to adopt that fatal way in the sense of enjoyment. Table 1 reveals an interesting finding that $82 \%$ agreed that friends play vital role in addiction and relapse. Because in childhood a man passes his time with his parents when he grows he find himself with friends and society fellows. It means that the personality of the person is influenced by them. Table 2 shows the respondents regarding the factor which play vital role to start the drugs. $46 \%$ of the respondents uses drugs just for the sack of enjoyment and $31 \%$ because of bad company. The reasons of drug use and relapse that most frequently cited reasons for initiating drug use were curiosity. The desire for new pleasurable experiences and wishes to be able to move in high circle of society the drugs that influence the brain function were taken to allay anxiety hunger or fatigue, forget worries, economic problems, social difficulties and attain mystical state. $81 \%$ of the respondents used multiple drug which shows that when the drug abusers uses multiple drug, these drugs had multiple adverse effect on their health, so there is less chances to improve the physical health drug abusers.74\% of the drug abusers were not satisfied with their act of addiction because they have lost their aim, ambitions and achievements. So they want to live in their society or community like others. 


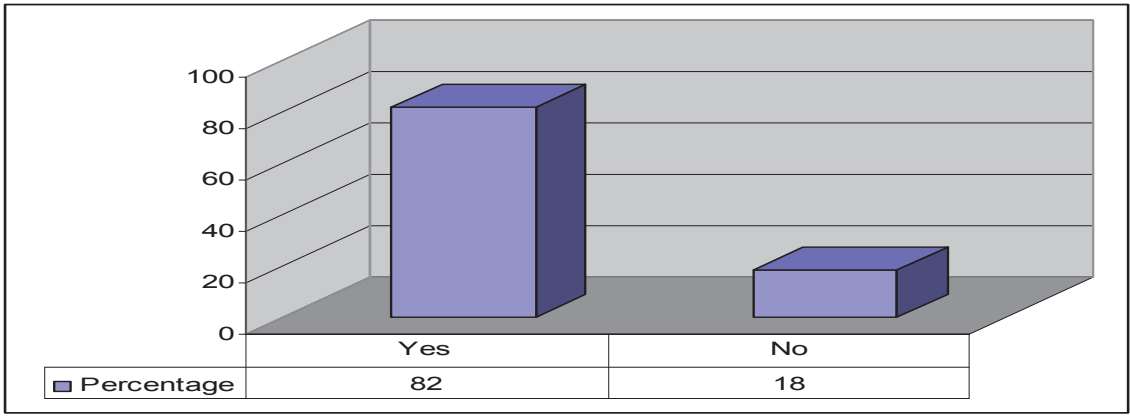

Table1: Role of friends in addiction and relapse

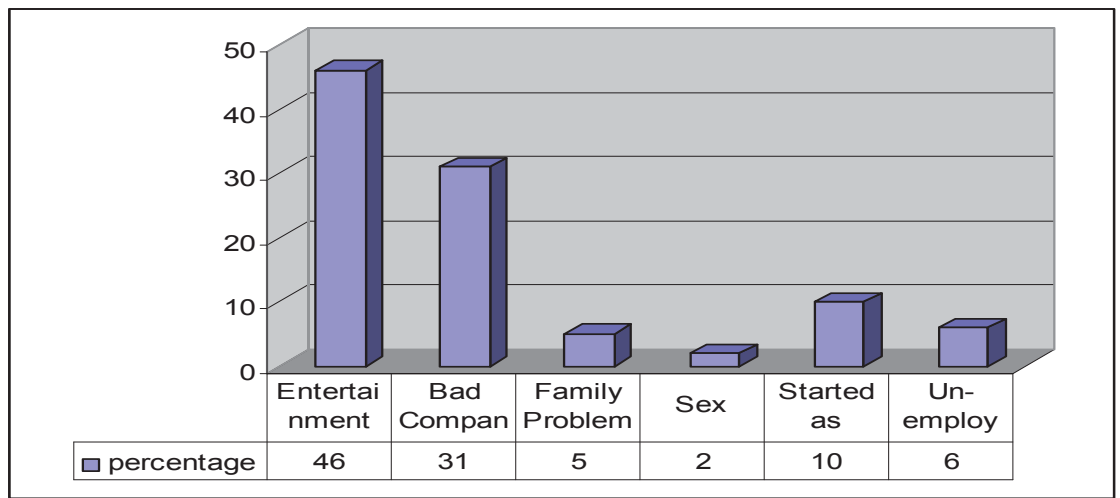

Table 2: Factors which play vital role to start the drugs

Table 3 shows that $82 \%$ of the respondents were agreed that society had a major contribution and is playing a major role in spread of addiction. This means that society is like a shawl of the soul of a person by the airy views of the cloth wear by the person. So the table enlight the truth that society is directly responsible for drug addiction and same kind of other problems and reasons also put up man into the depth of drugs. Table 4 is about the respondents regarding to the factors/causes which involve to increase the relapse ration among them. By analyzing it is very clear that some factors play major role to increase the relapse ratio. Now the question is, how we can control the psychological dissatisfaction. The key factor behind is stress, anxiety, psychological dissatisfaction etc. the impact of stress recently was high lightened when researcher documented increased rates of drug abuse and alcohol consumption.

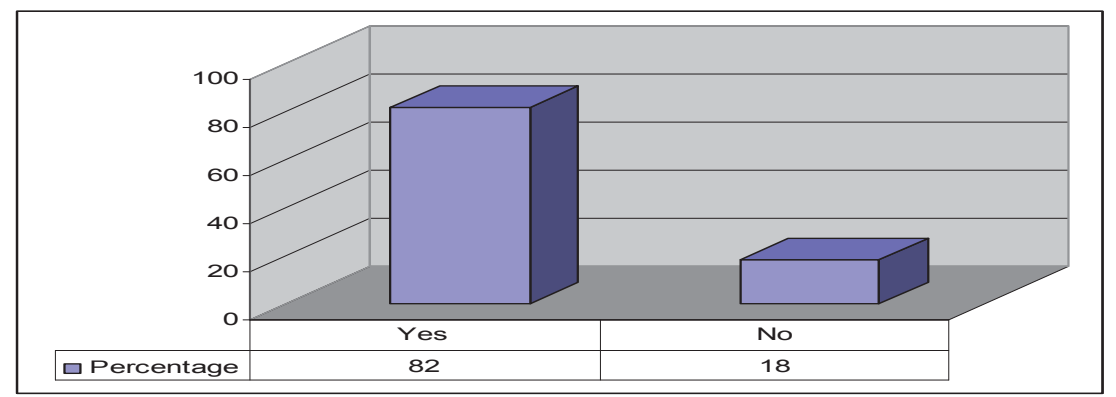

Table 3: Role of society in spread of drug addiction 


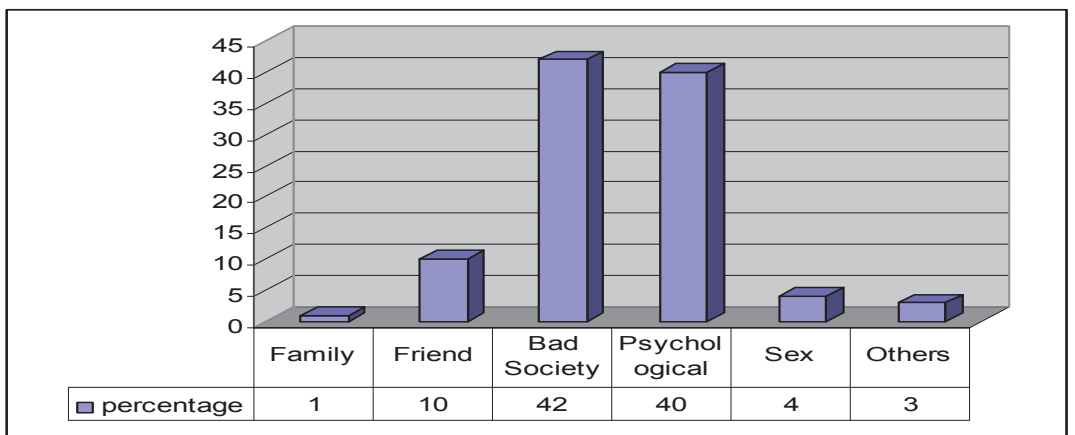

Table 4: Factors/Causes which involve increasing the relapse ratio

$72 \%$ respondent's family members do a lot of efforts to leave drug but the question is why the addiction and relapse ratio is consistently increasing. The reason is that may be in our society there is a lack of motivation and counseling. At the end the respondents showed the suggestion of relapse control. $48 \%$ respondents agreed that relapse could be controlled by strong will power, they said that strong will power is the major tool for the control of drug relapse changing company and unavailability of drugs is another option to control drug.

\section{Conclusion and Recommendation}

If we share the beliefs that children and young people are precious asset for human population and future human capital, we need to invest our intellect, social resources and a range of resources in nurturing them and protecting them against two of the deadly social conditions of the $21^{\text {st }}$ century, drugs and relapse. There is no easy solution to the challenges posed by drug abuse and relapse, particularly amongst children and young people as the most vulnerable groups of the population. The complexity of these two issues requires careful and non-emotive planning and intervention. They may change the face and character of our human services, educational and social institutions. However, the government in the name of social development should continue to take the lead in creating policy environments that facilitate appropriate intervention, provide resources and national infrastructure, research findings and research funding and accountability systems. Civil society structures face the challenges of creating and sustaining effective delivery mechanisms that are collaborative, multi-faceted, preventive and remedial in character. The family in particular should seriously re-examine its role and responsibly as a socializing and nurturing agent. Young people have powerful organization, which should play a very visible and important role in addressing and responding to needs of young people.

\section{References}

Joe, G. W., Chastain, R. L., Marsh, K. L., and Simpsons, D. D., 1985. Opium Recidivism Factor. Taxas A \& M University Behavioral Research Program pp 30-36

Khalid, I., Fareed, A., and Arshad, M., 2004. Demographic Characteristics of Drug Addicts. Journal of Rawalpindi Medical College Vol. 8(1) pp 26-30

Midgley, J., 1995. Social Development. The Development Perspective in Social Welfare SAGE Publication pp 20-30

National Mental Health, 2002. Report of Australia Health Ministries, Canberra pp 20-25

Nowinski, J., 1990. Substances Abuse in Adolescent and Young Adults. A guide to Treatment. Noron and Company pp 34

Wanigaratne, S., Wallance, W., and Phullin, J. 1990. Relapse Prevention fore addict behavior Oxford, Blackwell, pp 725-726 